\title{
Разработка методики адсорбционной иммобилизации трипсина на ионообменных смолах
}

\author{
(C) 2021 Ольшанникова С.С. ${ }^{1}$, Сакибаев Ф.А. ${ }^{1}$, \\ Холявка М.Г. ${ }^{1,2}$, Артюхов В.Г. ${ }^{1}$ \\ ${ }^{1}$ Воронежский государственный университет, Воронеж \\ ${ }^{2}$ Севастопольский государственный университет, Севастополь
}

Поступила в редакцию 27.02.2021 г.

DOI: $10.17308 /$ sorpchrom.2021.21/3474

Трипсин (КФ 3.4.21.4) является наиболее популярным ферментом в промышленности и биомедицине. Однако невозможность повторного использования и сложность восстановления делают его масштабное промышленное применение неэффективным и дорогостоящим. Решить эту проблему можно с помощью иммобилизации трипсина на ионообменных материалах. Целью работы было исследование закономерностей адсорбционной иммобилизации трипсина на ионообменных смолах для создание гетерогенного препарата на его основе, доступного для использования в отечественных лабораториях и промышленности.

Предложена методика иммобилизации трипсина на разных типах ионообменных смол: катионных смолах с функциональными группами - $\mathrm{SO}_{3} \mathrm{H}$ (КУ-2, КУ-2-8чC, IMAC-HР111), анионных смолах с активными группами $-\mathrm{N}^{+}\left(\mathrm{CH}_{3}\right)_{3}$ (AB-17-2П, Purolite A100), вторичными и третичными алифатическими аминогруппами и пиридиновыми группами (АВ-16-ГС), вторичными, третичными и четвертичными алифатическими аминогруппами (ЭДЭ-10-П). Подготовку к работе ионообменных смол и сорбционную иммобилизацию трипсина осуществляли по стандартным методикам. Измерение содержания белка в иммобилизованных препаратах трипсина проводили по модифицированному методу Лоури, протеазную активность образцов определяли на субстрате азоказеине, а эстеразную активность - на субстрате $N$ - $\alpha$-бензоил- $D L$-аргинин- $n$-нитроанилиде (BAPNA).

Полученные препараты трипсина, иммобилизованного на ионообменных смолах, могут стать основой для решения ряда проблем, возникающих при создании сорбентов для очистки сточных вод, при разделении и очистке различных веществ в химической промышленности, а также изучении потоков питательных веществ и внесении удобрений на полях.

Установлено, что оптимальное соотношение содержания белка (мг на г носителя), общей протеазной активности (ед на мл раствора) и удельной протеазной активности (ед на мг белка) наблюдается при иммобилизации трипсина на носителе ЭДЭ-10-П с фосфатным буфером, pH 11.0 и $\mathrm{NaOH}-\mathrm{KCl}$ буфером, pH 12.0. Оптимальное соотношение содержания белка, общей эстеразной активности и удельной эстеразной активности получено при адсорбции трипсина на АB-16-ГС с $\mathrm{NaOH}-\mathrm{KCl}$ буфером, $\mathrm{pH}$ 12.0 .

Ключевые слова: трипсин, ионообменные смолы, иммобилизация, адсорбция, протеазная активность, эстеразная активность.

\section{Введение}

Ионообменные смолы нашли широкое применение во многих отраслях хозяйственной деятельности человека. В основном их используют для смягчения и обессоливания воды, при очистке возвратных и сточных вод, для разделения и очистки различных веществ в химической промышленности, в роли катализаторов для органического синтеза [1-3]. Ионообменные смолы применяют в качестве динамических обменников в лаборатории или в промышленности [4-6]. 
Ионообменные смолы представляют собой полимерные гранулы с различными функциональными группами, способные связывать ионы противоположного заряда. В зависимости от обмена ионами, ионообменники можно разделить на катионо- и анионообменные. Одновременный обмен катионов и анионов может также выполняться с использованием определенных типов материалов (амфотерные ионообменники) [7]. Содержание противоиона в ионообменной смоле определяется как ионообменная емкость. Другой важной характеристикой ионообменных материалов является селективность [8]. В настоящей работе мы использовали разные типы ионообменных смол: катионные смолы с функциональными группами - $\mathrm{SO}_{3} \mathrm{H}$ (КУ-2, КУ-2-8чС, IMAC-НР111), анионные смолы с активными группами $-\mathrm{N}^{+}\left(\mathrm{CH}_{3}\right)_{3}$ (AB-17-2П, Purolite A100), вторичными и третичными алифатическими аминогруппами и пиридиновыми группами (AB-16ГС), вторичными, третичными и четвертичными алифатическими аминогруппами (ЭДЭ-10-П) [9-15]. Ионообменные смолы могут выступать в качестве носителя при иммобилизации ферментов, тем самым они расширяют диапазон своего применения в промышленности и фармации $[16,17]$.

Трипсин (КФ 3.4.21.4) является членом семейства сериновых протеаз, которые катализируют гидролиз пептидных, сложноэфирных и амидных связей. Это наиболее популярный фермент в промышленности и биомедицине $[18,19]$. Трипсин применяется для отделения прикрепленных клеточных линий в культуре клеток. Известно его использование в моющих средствах для удаления белковых пятен и при обработке кожи. Выявлено, что трипсин обладает антибактериальной активностью. Благодаря этому можно решить проблему бактериальной загрязненности воды и почвы. Широкое применение трипсина связано с его детально изученной субстратной специфичностью. В промышленных условиях гидролиз белка трипсином часто остается неполным. Кроме того, трудно масштабировать процессы гидролиза, осуществляемые трипсином из-за его низкой стабильности и автолиза [20-23]. Невозможность повторного использования и сложность восстановления делает промышленное применение трипсина неэффективным и дорогостоящим. Решить эти проблемы можно с помощью его иммобилизации на нерастворимых носителях. Связывание с полимерной матрицей ионообменных смол уменьшает диффузию фермента в растворе и увеличивает функциональную площадь его поверхности. Другими преимуществами иммобилизации энзимов являются возможность их повторного использования, низкая скорость протеолиза, а также стабильность в течение длительного времени [24-26].

В связи с вышесказанным, целью работы было исследование закономерностей адсорбционной иммобилизации трипсина на ионообменных смолах.

\section{Экспериментальная часть}

В качестве объекта исследования был выбран трипсин быка (MP biomedicals, США), субстратами для гидролиза служили азоказеин и $N$ - $\alpha$-бензоил- $D L$-аргинин- $n$-нитроанилид (BAPNA) (Sigma, США), носителями для иммобилизации ионообменные смолы КУ-2, КУ-2-8чС, IMAC-HP111, АВ-16-ГC, АВ-17-2П, Purolite A100, ЭДЭ-10-П. В качестве иммобилизационной среды использовали следующие буферы: $0.05 \mathrm{M}$ фосфатный с pH 6.5 и 11.0, 0.05 М глициновый с $\mathrm{pH}$ 9.0, 0.05 M NaOH-KCL c pH 12.0. Кондиционирование ионообменников проводили по методике [27].

Методика адсорбционной иммобилизации трипсина. К 1 г ионообменной смолы добавляли $20 \mathrm{~cm}^{3}$ раствора фермента (в концентрации $1 \mathrm{mг} / \mathrm{cm}^{3}$ ), инкубировали в течение 4 часов с периодическим перемешиванием. Суспензию центрифугировали при $1.500 \mathrm{~g}$ в течение 10 мин. Образовавшийся осадок промывали 50 мМ трис-HCl буфером (pH 7.5) до 
отсутствия в промывных водах белка (контроль осуществляли на спектрофотометре СФ-2000 при $\lambda=280 \mathrm{Hм}$ ).

Метод определения протеазной активности трипсина. Определение протеазной активности трипсина проводили на субстрате азоказеине [28]. К 50 мг иммобилизованного образца добавляли 200 мкл $0.05 \mathrm{M}$ трис-HCl буфера с рН 7.5, 800 мкл азоказеина $(0.5 \%$ в $0.05 \mathrm{M}$ трис- $\mathrm{HCl}$ буфере, $\mathrm{pH} 7.5)$ и инкубировали 2 часа при $37^{\circ} \mathrm{C}$. Далее добавляли 800 мкл трихлоруксусной кислоты (ТХУ) (5\%), инкубировали 10 минут при $4^{\circ} \mathrm{C}$, затем центрифугировали в течение 3 мин при 13 тыс об/мин для удаления негидролизованного азоказеина. К 1200 мкл супернатанта добавляли 240 мкл 3\% NaOH для нейтрализации кислоты, после чего измеряли оптическую плотность опытной пробы при 410 нм в 10 мм кювете. Контрольная проба содержала 800 мкл азоказеина, 800 мкл ТХУ, 50 мг образца и 200 мкл буфера (иммобилизованный фермент в контрольную пробу вносили последним, остальные операции для нее делали аналогично опытным пробам).

Единицей протеазной активности служило количество трипсина, которое в условиях эксперимента гидролизует 1 мкМ азоказеина за 1 мин. Удельную протеазную активность рассчитывали по формуле:

$$
\Pi A=\frac{A}{1000 \times 120 \times 200 \times C},
$$

где ПА - протеолитическая активность препарата, мкМ/мин на 1 мг белка; $A$ - оптическая плотность раствора при 410 нм;

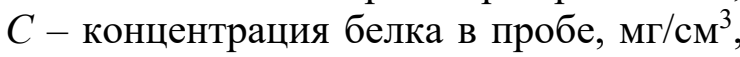
измеренная по методу Лоури; 120 - время инкубации в минутах; 200 - объем пробы, мкл; 1000 - коэффициент для пересчета в мкМ.

Определение эстеразной активности трипсина. Определение эстеразной активности трипсина проводили на субстрате $N$ - $\alpha$-бензоил- $D L$-аргинин- $n$-нитроанилиде (BAPNA) [29]. К 50 мг образца добавляли 400 мкл BAPNA $\left(1 \mathrm{мг} / \mathrm{cm}^{3}\right)$ и 400 мкл $0.2 \mathrm{M}$ фосфатного буфера с $\mathrm{pH}$
7.4, содержащего 0.04 М раствор цистеина. Инкубировали раствор 2 часа при $37^{\circ} \mathrm{C}$, останавливали реакцию 800 мкл $1 \mathrm{M} \mathrm{HCl}$. Измеряли оптическую плотность образцов при длине волны 410 нм. Контрольная проба содержала 400 мкл BAPNA, 400 мкл $1 \mathrm{M} \mathrm{HCl,} 50$ мг образца и 400 мкл буфера (иммобилизованный фермент в контрольную пробу вносили последним, остальные операции для нее делали аналогично опытным пробам).

Единицей эстеразной активности служило количество трипсина, которое в условиях эксперимента гидролизует 1 мкM $N$ - $\alpha$-бензоил- $D L$-аргинин- $n$-нитроанилида за 1 минуту. Удельную эстеразную активность рассчитывали по формуле:

$$
Э A=\frac{A}{1000 \times 120 \times 400 \times C},
$$

где ЭA - эстеразная активность препарата, мкМ/мин на 1 мг белка; $A$ - оптическая плотность раствора при 410 нм; $C$ - концентрация белка в пробе, мг $/ \mathrm{cm}^{3}$, измеренная по методу Лоури; 120 - время инкубации в минутах; 400 - объем пробы, мкл; 1000 - коэффициент для пересчета в мкМ

Содержание белка в иммобилизованных препаратах трипсина определяли модифицированным методом Лоури [30].

Все экспериментальные исследования осуществляли минимум в 8-кратной повторности. Статистическая обработка полученных результатов проводилась при уровне значимости 5\% с использованием $\mathrm{t}$-критерия Стьюдента.

\section{Обсуждение результатов}

При иммобилизации трипсина на ионообменных материалах необходимо учитывать такие важные показатели, как заряды носителя и фермента. Значение $\mathrm{pI}$ трипсина составляет 10.8 [15], поэтому, чтобы обеспечить ферменту необходимый заряд, в качестве иммобилизационной среды для его адсорбции на катионообменниках КУ-2, КУ-2-8чС и IMACНР111 мы использовали 0.05 М фосфатный буфер с рН 6.5 и 0.05 М глициновый 


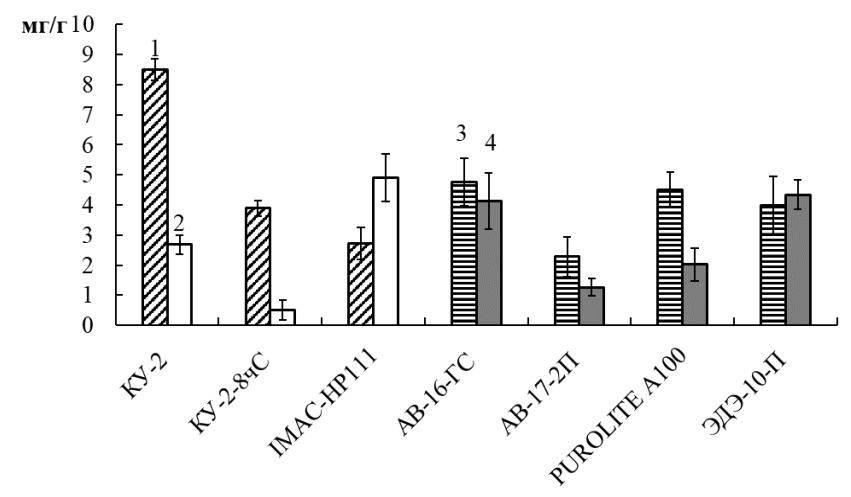

Рис. 1. Содержание белка (мг/г носителя) в препаратах трипсина, иммобилизованного адсорбционным методом на ионообменных смолах с использованием следующих

буферов: $1-0.05 \mathrm{M}$ фосфатный с рН 6.5; $2-0.05$ М глициновый с $\mathrm{pH} 9.0$; $3-0.05 \mathrm{M}$ фосфатный с $\mathrm{pH} 11.0 ; 4-0.05 \mathrm{M} \mathrm{NaOH}-\mathrm{KCL}$ c pH 12.0

Fig. 1. Protein content (mg/g carrier) in trypsin preparations immobilized by the adsorption method on ion-exchange resins using the following buffers: $1-0.05 \mathrm{M}$ phosphate with $\mathrm{pH} 6.5$; $2-0.05 \mathrm{M}$ glycine with $\mathrm{pH} 9.0 ; 3-0.05 \mathrm{M}$ phosphate with $\mathrm{pH} 11.0$; $4-0.05 \mathrm{M} \mathrm{NaOH}-\mathrm{KCl}$ with $\mathrm{pH} 12.0$

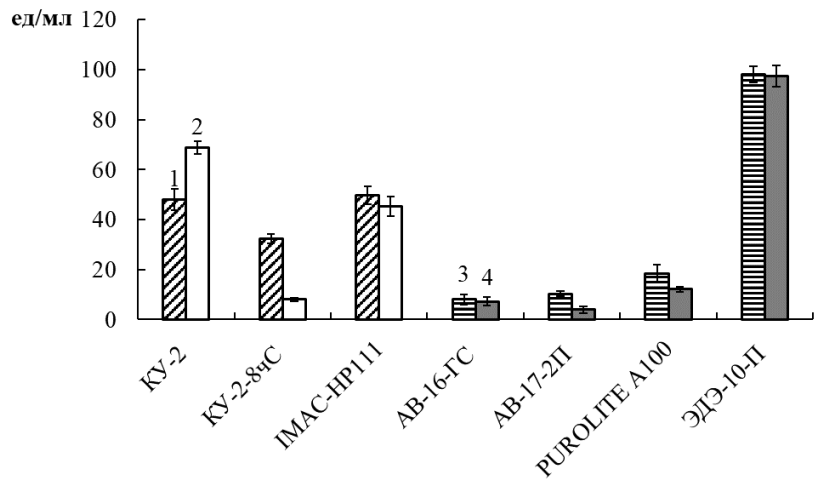

Рис. 2. Протеазная активность (ед/мл раствора) в препаратах трипсина, иммобилизованного адсорбционным методом на ионообменных смолах с использованием следующих буферов: $1-0.05 \mathrm{M}$ фосфатный с $\mathrm{pH} 6.5 ; 2-0.05$ М глициновый с $\mathrm{pH} 9.0 ; 3-0.05 \mathrm{M}$ фосфатный с $\mathrm{pH} 11.0 ; 4-0.05 \mathrm{M} \mathrm{NaOH}-\mathrm{KCL}$ c pH 12.0

Fig. 2. Protease activity ( $\mathrm{U} / \mathrm{ml}$ solution) in trypsin preparations immobilized by the adsorption method on ion-exchange resins using the following buffers: $1-0.05 \mathrm{M}$ phosphate with $\mathrm{pH}$ $6.5 ; 2-0.05 \mathrm{M}$ glycine with $\mathrm{pH} 9.0 ; 3-0.05 \mathrm{M}$ phosphate with $\mathrm{pH} 11.0 ; 4-0.05 \mathrm{M} \mathrm{NaOH}-\mathrm{KCl}$ with $\mathrm{pH} 12.0$

буфер с рН 9.0, а для иммобилизации на анионообменниках АВ-17-2П, АВ-16-ГС, ЭДЭ-10-П и Purolite A100 применяли 0.05 М фосфатный буфер с рН 11.0 и $0.05 \mathrm{M}$ $\mathrm{NaOH}-\mathrm{KCL}$ буфер с pH 12.0.

Наибольшее количество белка в гетерогенных препаратах (в мг на г носителя) наблюдалось при иммобилизации трипсина адсорбционным методом на матрице КУ-2 с фосфатным буфером с рН 6.5 (рис. 1). Высокие значения общей протеазной активности трипсина (в ед на мл раствора) были зарегистрированы при его иммобилизации на матрице ЭДЭ-10-П с фосфатным буфером, $\mathrm{pH} 11.0$ и $\mathrm{NaOH}-$ $\mathrm{KCl}$ буфером, pH 12.0 (рис. 2). Наибольшую удельную протеазную активность показали препараты трипсина, иммобилизованного с помощью адсорбционного метода на матрицах КУ-2 с глициновым буфером рН 9.0, ЭДЭ-10-П с фосфатным буфером, $\mathrm{pH} 11.0$ и $\mathrm{NaOH}-\mathrm{KCl}$ буфером, pH 12.0 (рис. 3).

При создании гетерогенных препаратов трипсина адсорбционным методом наибольшая эстеразная активность (в ед 


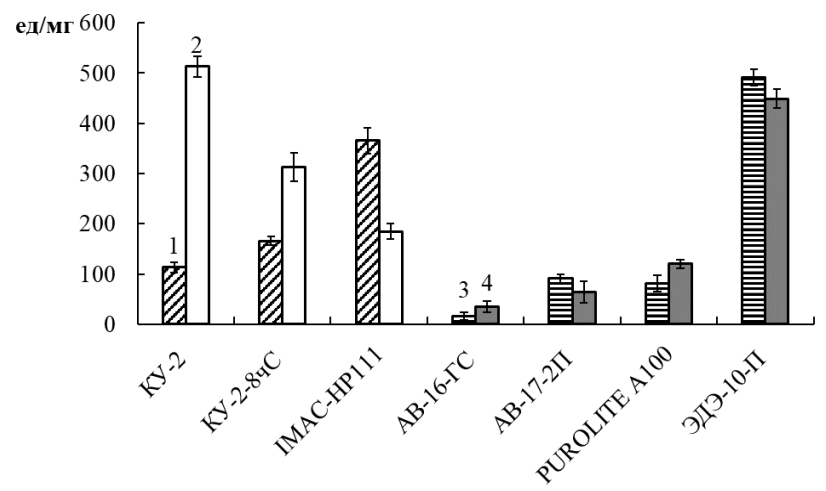

Рис. 3. Удельная протеазная активность (ед/мг белка) в препаратах трипсина, иммобилизованного адсорбционным методом на ионообменных смолах с использованием следующих буферов: $1-0.05$ М фосфатный с $\mathrm{pH} 6.5 ; 2-0.05$ М глициновый с $\mathrm{pH} 9.0$;

$3-0.05 \mathrm{M}$ фосфатный с $\mathrm{pH} 11.0 ; 4-0.05 \mathrm{M} \mathrm{NaOH}-\mathrm{KCL}$ c pH 12.0

Fig. 3. Specific protease activity (U/mg protein) in trypsin preparations immobilized by the adsorption method on ion-exchange resins using the following buffers: $1-0.05 \mathrm{M}$ phosphate with $\mathrm{pH} 6.5 ; 2-0.05 \mathrm{M}$ glycine with $\mathrm{pH} 9.0 ; 3-0.05 \mathrm{M}$ phosphate with $\mathrm{pH} 11.0 ; 4-0.05 \mathrm{M}$ $\mathrm{NaOH}-\mathrm{KCl}$ with $\mathrm{pH} 12.0$

на мл раствора) проявлялась при использовании носителя АВ-16-ГС с фосфатным буфером, $\mathrm{pH} 11.0$ и $\mathrm{NaOH}-\mathrm{KCl}$ буфером, pH 12.0 (рис. 4). Наибольшую удельную эстеразную активность показали препараты трипсина, иммобилизованного с помощью адсорбционного метода на матрице $\mathrm{AB}-16-\Gamma \mathrm{C}$ с $\mathrm{NaOH}-\mathrm{KCl}$ буфером с $\mathrm{pH} 12.0$ (рис. 5).

Вероятно, наличие у носителя функциональных сульфогрупп обеспечивает высокие показатели сорбции трипсина (особенно при значении $\mathrm{pH}$ среды 6.5, которое существенно ниже изоэлектрической точки сорбата), но при этом фермент находится в каталитически невыгодной конформации, что отрицательно сказывается как на его протеазной, так и на его эстеразной активностях. При повышении $\mathrm{pH}$ иммобилизационной среды до 9.0 протеазная активность адсорбированного на КУ-2 трипсина возрастает, подтверждая тот факт, что оптимизировав условия сорбции (состав, ионная сила, $\mathrm{pH}$ буфера), можно снизить влияние матрицы носителя на конформацию молекул фермента.

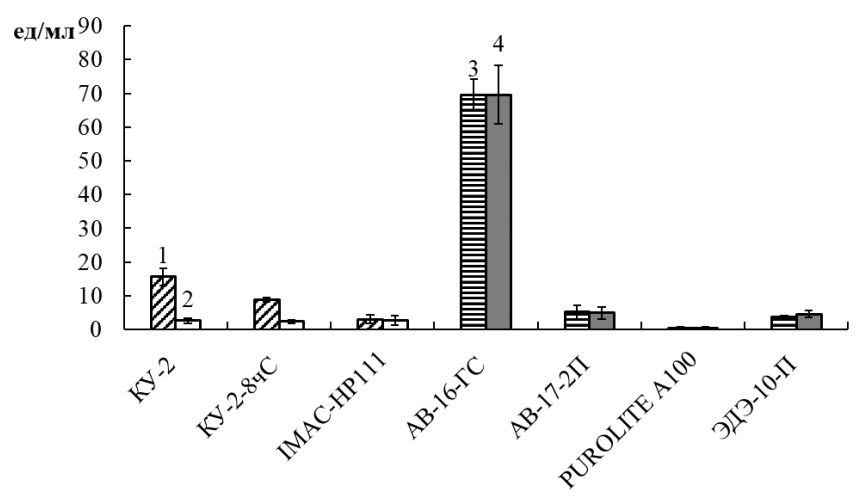

Рис. 4. Эстеразная активность (ед/мл раствора) в препаратах трипсина, иммобилизованного адсорбционным методом на ионообменных смолах с использованием следующих буферов: $1-0.05 \mathrm{M}$ фосфатный с $\mathrm{pH} 6.5 ; 2-0.05$ М глициновый с $\mathrm{pH} 9.0 ; 3-0.05 \mathrm{M}$ фосфатный с pH 11.0; $4-0.05$ M NaOH-KCL c pH 12.0

Fig. 4. Esterase activity (U/ml solution) in trypsin preparations immobilized by the adsorption method on ion-exchange resins using the following buffers: $1-0.05 \mathrm{M}$ phosphate with $\mathrm{pH} 6.5$; $2-0.05 \mathrm{M}$ glycine with $\mathrm{pH} 9.0 ; 3-0.05 \mathrm{M}$ phosphate with $\mathrm{pH} 11.0 ; 4-0.05 \mathrm{M} \mathrm{NaOH}-\mathrm{KCl}$ with $\mathrm{pH} 12.0$ 


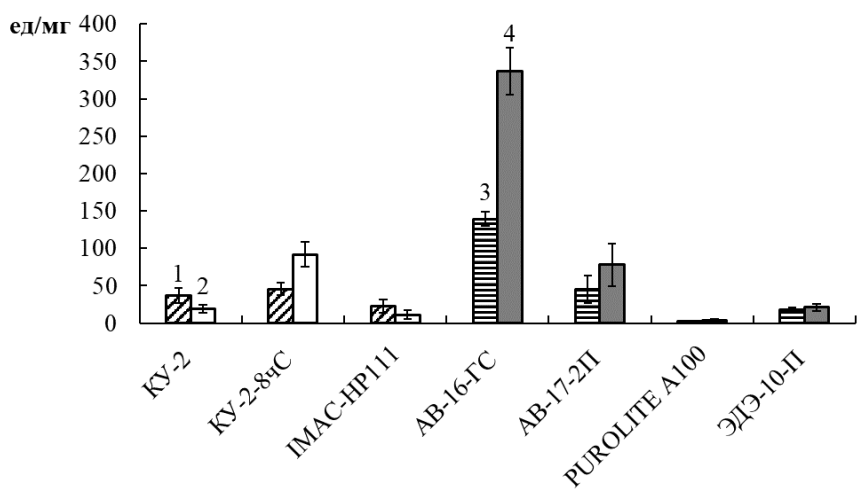

Рис. 5. Удельная эстеразная активность (ед/мг белка) в препаратах трипсина, иммобилизованного адсорбционным методом на ионообменных смолах с использованием следующих буферов: $1-0.05$ М фосфатный с $\mathrm{pH} 6.5 ; 2-0.05$ М глициновый с $\mathrm{pH} 9.0 ; 3-0.05$

М фосфатный с pH 11.0; $4-0.05 \mathrm{M} \mathrm{NaOH-KCL} \mathrm{c} \mathrm{pH} 12.0$

Fig. 5. Specific esterase activity (U/mg protein) in trypsin preparations immobilized by the adsorption method on ion-exchange resins using the following buffers: $1-0.05 \mathrm{M}$ phosphate with $\mathrm{pH} 6.5 ; 2-0.05 \mathrm{M}$ glycine with $\mathrm{pH} 9.0 ; 3-0.05 \mathrm{M}$ phosphate with $\mathrm{pH} 11.0 ; 4-0.05 \mathrm{M}$ $\mathrm{NaOH}-\mathrm{KCl}$ with $\mathrm{pH} 12.0$

Высокие значения протеазной активности были получены при иммобилизации трипсина при рН 11.0 и 12.0 на ЭДЭ-10-П, а эстеразной - на матрице AB-16-ГС, что указывает на перспективность носителей с функциональными вторичными и третичными алифатическими аминогруппами для сохранения (стабилизации) обоих типов активности трипсина.

\section{Заключение}

Таким образом, нами предложены методики иммобилизации трипсина путем адсорбции на ионообменных смолах с использованием различных буферных систем. Оптимальное соотношение содержания белка (мг на г носителя), общей протеазной активности (в ед на мл раствора) и удельной протеазной активности (в ед на мг белка) выявлено при иммобилизации трипсина на носителе
ЭДЭ-10-П с фосфатным буфером, pH 11.0 и $\mathrm{NaOH}-\mathrm{KCl}$ буфером, pH 12.0. Оптимальное соотношение содержания белка (мг на г носителя), общей эстеразной активности (в ед на мл раствора) и удельной эстеразной активности (в ед на мг белка) получено при адсорбции трипсина на AB$16-\Gamma \mathrm{C} \mathrm{c} \mathrm{NaOH-KCl} \mathrm{буфером,} \mathrm{pH} \mathrm{12.0.}$

Сочетание относительно недорогих компонентов позволит сделать доступным предлагаемый нами метод для отечественных лабораторий. В связи с этим разработанные образцы на основе иммобилизованного трипсина и ионообменных смол внесут свой вклад при создании препаратов для очистки сточных вод, для разделения и очистки различных веществ в химической промышленности, для изучения потоков питательных веществ и внесения удобрений на полях [31].

Работа выполнена при финансовой поддержке в форме гранта Президента Российской Федерации для государственной поддержки молодых российских ученых докторов наук МД-1982.2020.4. Соглашение 075-15-2020-325. 


\section{Список литературы}

1. Milyutin V.V., Kharitonov O.V., Firsova L.A., Nekrasova N.N. et al. // Journal of Radioanalytical and Nuclear Chemistry. 2020. Vol. 325. pp. 667-671.

2. Holyavka M.G., Kondratyev M.S., Lukin A.N., Agapov B.L. et al. // International Journal of Biological Macromolecules. 2019. Vol. 138. pp. 681-692.

3. Бруцкус Т.К., Замбровская Е.В., Самборский И.В. Иониты. Каталог. Черкассы. 1975. $36 \mathrm{c}$.

4. Бачерникова С.Г., Михалькова А.И., Есенкова Н.П., Лейкин Ю.А. и др. // Экологические системы и приборы. 2005. № 3. С. 5152.

5. Холявка М.Г., Кондратьев М.С., Терентьев В.В., Самченко А.А. и др. // Биофизика. 2017. T. 62. № 1. C. 9-16.

6. Qian P., Schoenau J.J. // Canadian Journal of Soil Science. 2002. Vol. 82. No 1. pp. 9-21.

7. Полянский Н.Г., Горбунов Н.В., Полянская Н.Л. Методы исследования ионитов. Москва. Химия. 1976. 208 с.

8. Горбунов Н.В., Полянский Н.Г. // Журнал физической химии. 1978.Т. 52. № 5. С. 1259-1262.

9. Kartsova L.A., Markova O.V. // Journal of Analytical Chemistry. 2000. Vol. 55. No 7. pp. 653-656.

10.Hassan M.M., Carr C.M. // Chemosphere. 2018. Vol. 209. pp. 201-219.

11.Лейкин Ю.А. // Сорбционные и хроматографические прочессы. 2004. Т. 4. № 5. С. 606-624.

12.Levchuk I., Rueda Márquez J.J., Sillanpää M. // Chemosphere. 2018. Vol. 192. pp. 90-104.

13. Черепкова Ю.А., Котова Д.Л., Селеменев В.Ф., Крысанова Т.А. и др. // Журнал физической химии. 2005. Т. 79. № 4. С. 716-720.

14.Мироненко Н.В., Михина И.А., Брежнева Т.А., Селеменев В.Ф. // Сорбиионные и хроматографические проиессы. 2008. Т. 8. № 3. C. 513-520.

15.Холявка М.Г., Наквасина М.А., Артюхов В.Г. Практикум по биотехнологии: иммобилизованные биологические объекты в системе лабораторных работ. Воронеж: Издательский дом ВГУ. 2017. 161 с.
16.Осипова Т.А., Тишков В.И., Варфоломеев С.Д. // Вестник Моск. ун-та. Серия 2: Химия. 2014. Т. 55. № 2. С. 59-70.

17.Кузнецов М.А., Нестеренко П.Н., Васияров Г.Г., Староверов С.М. // Прикладная биохимия и микробиология. 2006. Т. 42. № 6. С. 615-623.

18.Кретович В.Л. Введение в энзимологию. М. Наука. 1986. 336 с.

19.Woodard S.L., Mayor J.M., Bailey M.R., Barker D.K. et al. // Biotechnol Appl Biochem. 2003. Vol. 38. pp. 123-30.

20.Логинова О.О., Холявка М.Г., Артюхов В.Г. // Биофармачевтический журнал. 2015. № 2. C. 13-16.

21.Siddiqui I., Husain Q. // Colloids and surfaces. B, Biointerfaces. 2018. Vol. 173. pp. 733741.

22.Сливкин А.И., Беленова А.С., Холявка М.Г., Богачев М.И. и др. // Сорбичинные и хроматографические проиессы. 2013. Т. 13. № 1. C. 53-59.

23.Холявка М.Г., Артюхов В.Г., Сазыкина С.М., Наквасина М.А. // Химико-фармащевтический журнал. 2017. Т. 51. № 8. С. 39-43.

24.Мосолов В.В. Протеолитические ферменты. М. Наука. 1971. 404 с.

25.Дейнека В.И. // Журнал физической химии. 2008. Т. 82. № 6. С. 1028-1032.

26.Тривен М.Д. Иммобилизованные ферменты. М. Мир. 1983. 213 с.

27.Полянский Н.Г., Горбунов Н.В., Полянская Н.Л. Методы исследования ионитов. М. Химия. 1976. 208 с.

28.Sabirova A.R., Rudakova N.L., Balaban N.P., Ilyinskaya O.N. et al. // FEBS Lett. 2010. Vol. 584. No 21. 4419-4425.

29.Erlanger D.F., Kokowski N., Cohen W. // Arch. Biochem. Biophys. 1961. Vol. 95. pp. 271278.

30.Lowry O.H., Rosebrough N.J., Faar A.L., Randall R.J. // The Journal of Biological Chemistry. 1951. Vol. 193. pp. 265-275.

31.Холявка М.Г., Артюхов В.Г. Иммобилизованные биологические системы: биофизические аспекты и практическое применение: учебное пособие. Воронеж: Издательский дом ВГУ. 2017. $261 \mathrm{c.}$ 


\title{
Development of a technique for the adsorption immobilization of trypsin on ion-exchange resins
}

\author{
(C) 2021 Olshannikova S.S. ${ }^{1}$, Sakibaev F.A. ${ }^{1}$, \\ Holyavka M.G. ${ }^{1,2}$, Artyukhov V.G. ${ }^{1}$ \\ ${ }^{1}$ Voronezh State University, Voronezh \\ ${ }^{2}$ Sevastopol State University, Sevastopol
}

Trypsin (EC 3.4.21.4) is the most popular enzyme in industry and biomedicine. However, the impossibility of reuse and the complexity of recovery make its large-scale industrial use ineffective and expensive. This problem can be solved by immobilizing trypsin on ion-exchange materials. The aim of this study was investigation of the regularities of the adsorption immobilization of trypsin on ion-exchange resins for creation of a heterogeneous preparation based on it, available for use in domestic laboratories and industry.

A technique for the immobilization of trypsin on different types of ion exchange resins: cationic resins with functional groups $-\mathrm{SO}_{3} \mathrm{H}$ (KU-2, KU-2-8chS, IMAC-HP111), anionic resins with active groups $-\mathrm{N}^{+}\left(\mathrm{CH}_{3}\right)_{3}$ (AV-17-2P, Purolite A100), secondary and tertiary aliphatic amino groups and pyridine groups (AB-16-GS), secondary, tertiary and quaternary aliphatic amino groups (EDE-10-P) was proposed. The preparation of ion exchange resins and the sorption immobilization of trypsin were carried out according to standard methods. The protein content in the immobilized trypsin preparations was measured according to a modified Lowry method, the protease activity of the samples was determined using azocasein as the substrate, and the esterase activity was determined using $N$ - $\alpha$-benzoyl- $D L$-arginine- $p$-nitroanilide (BAPNA) as the substrate.

The obtained preparations of trypsin immobilized on ion-exchange resins can become the basis for solving a number of problems arising in the production of sorbents for waste water treatment, in the separation and purification of various substances in the chemical industry, as well as in the study of nutrient flows and fertilization in the fields.

It was found that the optimal ratio of the protein content (mg per $\mathrm{g}$ of the carrier), the total protease activity (units per $\mathrm{ml}$ of solution) and the specific protease activity (units per $\mathrm{mg}$ of protein) was observed when trypsin was immobilized on the EDE-10-P carrier with a phosphate buffer, $\mathrm{pH} 11.0$ and $\mathrm{NaOH}-\mathrm{KCl}$ buffer, $\mathrm{pH}$ 12.0. The optimal ratio of protein content, total esterase activity and specific esterase activity was obtained by adsorption of trypsin on AV-16-GS with $\mathrm{NaOH}-\mathrm{KCl}$ buffer, $\mathrm{pH}$ 12.0.

Keywords: trypsin, ion exchange resins, immobilization, adsorption, protease activity, esterase activity.

\section{References}

1. Milyutin V.V., Kharitonov O.V., Firsova L.A., Nekrasova N.N., Kozlitin E.A., Journal of Radioanalytical and Nuclear Chemistry, 2020, Vol. 325, pp. 667-671. DOI: 10.1007/s10967020-07277-4.

2. Holyavka M.G., Kondratyev M.S., Lukin A.N., Agapov B.L. et al., International Journal of Biological Macromolecules, 2019, Vol. 138, pp. 681-692. DOI: 10.1016/j.ijbiomac.2019.07.132.

3. Brutskus T.K. Ionites. Catalog. Cherkassy, $1975,36 \mathrm{p}$.

4. Bachernikova S.G., Mikhalkova A.I., Esenkova N.P., Leikin Yu.A. et al., Ecological systems and devices, 2005, Vol. 3, pp. 51-52.

5. Holyavka M.G., Kondratyev M.S., Terentyev V.V., Samchenko A.A. et al., Biophysics, 2017, Vol. 62, No 1, pp. 9-16.

6. Qian P., Schoenau J.J., Canadian Journal of Soil Science. 2002, Vol. 82, No 1, pp. 9-21. DOI:10.4141/S00-091.
7. Polyansky N.G., Gorbunov N.V., Polyanskaya N.L., Methods of research of ion exchangers, M., Chemistry, 1976, 208 p.

8. Gorbunov N.V., Polyansky N.G., Journal of Physical Chemistry, 1978, Vol. 52, No 5, pp. 1259-1262.

9. Kartsova L.A., Markova O.V., Journal of Analytical Chemistry, 2000, Vol. 55, No 7, pp. 653-656. DOI: 10.1007/BF02828000

10.Hassan M.M., Carr C.M., Chemosphere, 2018, Vol. 209, pp. 201-219. DOI: 10.1016/ j.chemosphere.2018.06.043.

11.Leikin Yu.A. Sorptsionnye I khromatograficheskie protsessy, 2004, Vol. 4, No 5 ,pp. 606-624.

12.Levchuk I., Rueda Márquez J.J., Sillanpää M., Chemosphere, 2018, Vol. 192, pp. 90-104. DOI: 10.1016/j.chemosphere.2017.10.101.

13.Cherepkova Yu.A., Kotova D.L., Selemenev V.F., Krysanova T.A. et al., Journal of Physical Chemistry, 2005, Vol. 79, No 4, pp. 716-720. 
14.Mironenko N.V., Mikhina I.A., Brezhneva T.A., Selemenev V.F., Sorptsionnye I khromatograficheskie protsessy 2008, Vol. 8, No 3, pp. 513-520.

15.Holyavka M.G., Nakvasina M.A., Artyukhov V.G., Voronezh, VSU Publishing House, 2017, $161 \mathrm{p}$.

16. Osipova T.A., Tishkov V.I., Varfolomeev S.D., Herald Mosk. un-that. Series 2: Chemistry, 2014, Vol. 55, No 2, pp. 59-70.

17.Kuznetsov M.A., Nesterenko P.N., Vasiyarov G.G., Staroverov S.M., Applied Biochemistry and Microbiology, 2006, Vol. 42, No 6, pp. 615-623.

18.Kretovich V.L. Vvedenie v enzimologiyu. M., Nauka, 1986, 336 p.

19.Woodard S.L., Mayor J.M., Bailey M.R., Barker D.K. et al., Biotechnol Appl Biochem, 2003, Vol. 38, pp. 123-30. DOI:10.1042/BA20030026.

20.Loginova O.O., Holyavka M.G., Artyukhov V.G., Biopharmaceutical journal, 2015, No 2, pp. 13-16.

21.Siddiqui I., Husain Q., Colloids and surfaces. B, Biointerfaces, 2018, Vol.173. pp. 733741. DOI: 10.1016/j.colsurfb.2018.10.021

22.Slivkin A.I., Belenova A.S., Holyavka M.G., Bogachev M.I. et al., Sorptsionnye I khromatograficheskie protsessy, 2013, Vol. 13, No 1, pp. 53-59.

Ольшанникова Светлана Сергеевна - аспирант кафедры биофизики и биотехнологии, Воронежский государственный университет, Воронеж

Сакибаев Фархат Адильжанович - аспирант кафедры биофизики и биотехнологии, Воронежский государственный университет, Воронеж

Холявка Марина Геннадьевна - д.б.н.. доцент кафедры биофизики и биотехнологии, Воронежский государственный университет, Воронеж; профессор кафедры «Физика» Севастопольского государственного университета, Севастополь

Артюхов Валерий Григорьевич - д.б.н., профессор, зав. кафедрой биофизики и биотехнологии, Воронежский государственный университет, Воронеж
23.Holyavka M.G., Artyukhov V.G., Sazykina S.M., Nakvasina M.A., Pharmaceutical Chemistry Journal, 2017, Vol. 51, No 8, pp. 39-43.

24.Mosolov V.V., Proteoliticheskiye fermenty, M., Science, 1971, 404 p.

25.Deineka V.I. Journal of Physical Chemistry, 2008, Vol. 82, No 6, pp. 1028-1032.

26.Triven M.D., Immobilizovannye fermenty, M., Mir, 1983, 213 p.

27.Polyanskij N.G., Gorbunov N.V., Polyanskaya N.L. Metody issledovaniya ionitov. M. Himiya. 1976. 208 p.

28.Sabirova A.R., Rudakova N.L., Balaban N.P., Ilyinskaya O.N. et al., FEBS Lett, 2010, Vol. 584, No 21, pp. 4419-4425. DOI: 10.1016/j.febslet.2010.09.049.

29.Erlanger D.F., Kokowski N., Cohen W., Biochem. Biophys, 1961, Vol. 95, pp. 271-278. DOI: 10.1016/0003-9861(61)90145-x.

30.Lowry O.H., Rosebrough N.J., Faar A.L., Randall R.J., The Journal of Biological Chemistry, 1951, Vol. 193, pp. 265-275.

31.Holyavka M.G., Artyukhov V.G., Voronezh: Voronezh State University Publishing House, 2017, 261 p.

Olshannikova Svetlana S. - postgraduate student, department of biophysics and biotechnology, Voronezh State University, Voronezh, e-mail: Olshannikovas@gmail.com

Sakibaev Farkhat A. - postgraduate student, department of biophysics and biotechnology, Voronezh State University, Voronezh, e-mail: farkhatlukum@gmail.com

Holyavka Marina G. - Ph.D. (biology), associate prof., department of biophysics and biotechnology, Voronezh State University, Voronezh, Professor of Physics Department, Sevastopol State University, Sevastopol, e-mail: holyavka@rambler.ru

Artyukhov Valery G. - Ph.D. (biology), professor, Head of the Biophysics and Biotechnology Department, Voronezh State University, Voronezh, e-mail: artyukhov@bio.vsu.ru 